ERJ

Engineering Research Journa!

Faculty of Engineering

Minouflya University

\title{
EFFECT OF CEMENT DUST COMPOSITION AND FLY ASH INCORPORATION ON THE PHYSICAL PROPERTIES AND STRENGTH OF BLENDED CEMENT
}

\author{
Sabry A. Ahmed \\ Faculty of Engineering, Zagazig University, Zagazig 44519, Egypt.
}

\begin{abstract}
In this study tests were conducted with two types of blended cement; one was cement kiln dust with ordinary Portland cement (CKD-OPC) and the other was a combination of cement kiln dust and fly ash with OPC (CKD-FA-OPC). Three CKDs having different chemical compositions were collected from three different plants and mixed with OPC to produce blended cement 5 to $50 \%$ of CKD. One of these CKDs, which satisfy the best performance in CKD-OPC blends, was used as an activator to fly ash in CKD-FA-OPC blends. In these blends the total waste materials (CKD+FA) were used as a partial replacement of $5,10,15$ and $20 \%$ of the cement content, and the CKD and 'FA were combined at different ratios; where the percentage of CKD to the total waste materials was $0,30,50$ and $70 \%$. The blends were tested for their water requirements for normal consistency, 'setting times, soundness and compressive strength at 7 and 28 days age. Results of these tests were compared to those of OPC. It was found that the CKD with lower contents of harmitul oxides $\left(\mathrm{SO}_{3}, \mathrm{~K}_{2} \mathrm{O}, \mathrm{Na}_{2} \mathrm{O}, \mathrm{Cl}^{-}\right.$and free $\mathrm{CaO}$ ) could be used in the production of blended cement with quantities up to $35 \%$ of the cement content. The physical properties of these blends were very close to those of $\mathrm{OPC}$, and their compressive strengths were adequate. Also, when a proper CKD to FA ratio was used; the alkalis from CKD activated the hydration of FA and leading to a blend with satisfactory performance. CKD-FA-OPC blends with $90 \%$ OPC and not more than 5\% FA had physical properties and strength comparable to those of OPC.

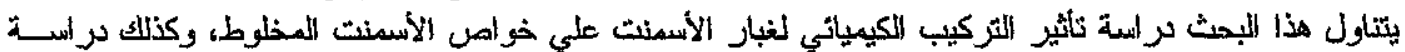

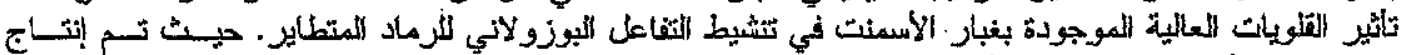

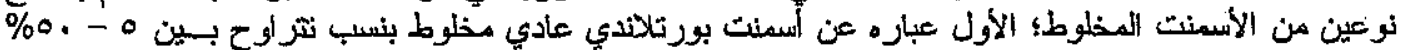

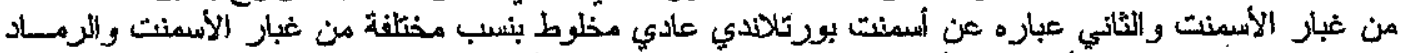

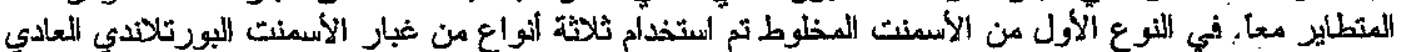

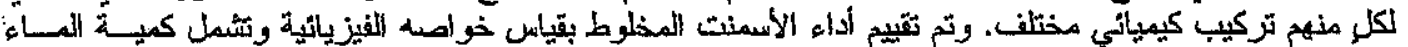

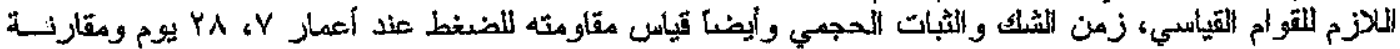

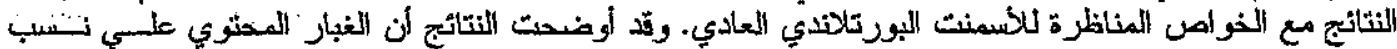

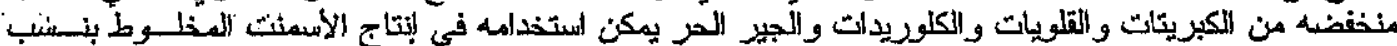

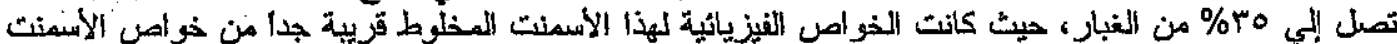

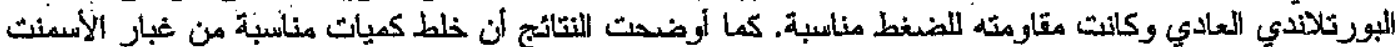

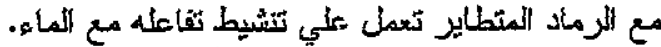

Keywords: Cement kiln dust; Fly ash; Blended cement; Chemical composition; Physical properties; Compressive strength.

\section{INTRODUCTION}

Cement kiln dust (CKD) is the fine-grained, solid and highly alkaline waste removed from cement kiln exhaust gas by air pollution control devices. Actually, the chemical composition of CKD is quite variable from source to source due to variations in the kind of raw materials and fuel used, as well as the production method or kiln type. It is primarily made up of a variable amount of fine calcined and uncalcined feed materials, fine cement clinker, fuel combustion by-products and condensed alkali compounds [1]. The main component of CKD is lime $(\mathrm{CaO})$. Other compounds include $\mathrm{SiO}_{2}, \mathrm{Al}_{2} \mathrm{O}_{3}, \mathrm{Fe}_{2} \mathrm{O}_{3}$, $\mathrm{K}_{2} \mathrm{O}, \mathrm{Na}_{2} \mathrm{O}, \mathrm{Cl}^{-}$, etc [2]. Due to the variability in dust composition, ASTM advises that use of CKD should be undertaken only after the material's characteristics have been properly evaluated with respect to the intended application [3]. ASTM also recommends that frequent tests to be performed until the degree of variability has been established.

Because much of the CKD contains actually unreacted raw material, large amounts of it can be 
treated by removing alkalis, chlorides and sulfates and recycled back into the production process as kiln feed. The treatment processes of CKD include leaching with water, leaching with potassium chloride solution, alkali volatilization, recovery scrubbing and fluid bed dust recovery [4]. CKD not returned to the production process is typically disposed in land-based disposal units (i.e., landfills, waste piles or surface impoundments), although some is sold for beneficial reuse.

Due to the high alkaline content of CKD and cost of treatment process, most of the material is disposed off on site without any further reuse or reclamation; therefore, many researchers have tried to reuse CKD in a variety of applications $[2,5,6]$. Among them the CKD was extensively used as a partial replacement of different types of cement; e.g. OPC, blast furnace slag cement (BFSC) and sulfate resistant cement (SRC). It was found that the direct replacement of CKD instead of SRC or BFSC was more effective than the recycling of dust with cement raw materials. This forms unflavored clinker phase during the firing in cement kilns due to the effect of high alkalinity of dust on the nature of clinker phases [7]. Addition of CKD increases the water demand for normal consistency of OPC and BFS pastes, and decreases the setting time. Free lime content of CKD-OPC cement pastes increases sharply up to 7 days, and later slowly. The free water increases with the increase in the quantity of $\mathrm{CKD}$ [8]. With respect to strength, the addition of CKD decreases the compressive strength of hardened OPC mortar. This decrease was slight at lower contents of C.KD, up to $6 \%$, and high at higher contents of CKD. On the other hand, the hardened slag cement mortar with $5 \%$ CKD gives a compressive strength higher than that without CKD as a result of the activation of hydration of slag. At 15 and $20 \% \mathrm{CKD}$, the compressive strength of the slag cement mortar decreases significantly [8].

More efficient use of CKD can be achieved through utilization of $\mathrm{CKD}$ as an activator for fly ash or slag to create cementitious binders of superior performance $[9,10]$. Shah and Wang [11] employed different activation methods to activate hydration of CKD-FA binders, which includes chemical, thermal and mechanical activations. For chemical activation, $\mathrm{NaOH}$ was added into the CKD-FA binder as a percentage of 2 and $5 \%$ by weight of binder. Curing temperatures of $38^{\circ} \mathrm{C}$ and $50^{\circ} \mathrm{C}$ were considered for thermal activation and the results were compared with that at normal curing temperature of $24^{\circ} \mathrm{C}$. Different grinding regimes were selected for mechanical activation, and they were simple blending, ball mill grinding, vibratory mill grinding and combined grinding using ball and vibratory mill grinding.
The experimental results of Shah and Wang [11] showed that $\mathrm{NaOH}$ addition might accelerate chemical dissolution but depressed crystal (ettringite) formation during the binder hydration. With the increase of $\mathrm{NaOH}$ addition, the ettringite formed in CKD-FA pastes decomposed at a reduced temperature. Curing at elevated temperatures had more significant influence on CKD-FA binder strength; than on OPC strength development, and appears to be more effective for CKD-FA binder strength improvement than $\mathrm{NaOH}$ addition. Grinding process reduces not only the particle size but also the crystalline phases of the materials; thus improving binder reactivity. Vibratory grinding for 4 hours provides the most success for mechanical activation among all grinding methods used.

\section{OBJECT OF THE PRESENT WORK}

The object of the present work. was to investigate the effect of CKD chemical composition on the properties of blended cement, and to study the role of alkalis containing CKD on activation of fly ash hydration. Thus, two types of blended cements were produced using three CKDs with different chemical compositions, all of them were by-products of OPC, and one type of fly ash. The jhysical properties and strength of the blended cements were measured and compared to those of OPC

\section{EXPERIMENTAL PROGRAM}

The materials used in this study were ordinary Portland cernent, cement kiln dust, fly ash and natural siliceous sand. Three untreated raw cement kiln dusts were collected from three different locations having different chemical compositions, while all of them were by-products of OPC. They were denoted here as Types I, II and III. The chemical analysis of OPC and the three types of CKDs used in this investigation are given in Table 1. The chemical composition of CKDs consists of the same fundamental components of OPC, but with different proportions. The total lime contents $(\mathrm{CaO})$ in CKDs were about $50 \%$ of their composition, which were less than that of OPC. Their contents of alkalis $\left(\mathrm{K}_{2} \mathrm{O}\right.$ and $\left.\mathrm{Na}_{2} \mathrm{O}\right)$, sulfate $\left(\mathrm{SO}_{3}\right)$ and chloride (CI) were relatively high, as compared to those of OPC. Also, the loss of ignition was considerably higher in CKDs. Comparing the chemical compositions of the three CKDs with each other, show that the harmful oxides $\left(\mathrm{SO}_{3}, \mathrm{~K}_{2} \mathrm{O}, \mathrm{Na}_{2} \mathrm{O}, \mathrm{Cl}^{-}\right.$ and free $\mathrm{CaO}$ ) were relatively low in CKD of Type $\mathrm{I}$, medium in CKD of Type II and high in CKD of Type III, as shown in Table 1.

Fly ash resulting from coal combustion in the power generation plant was used in this study; its chemical analysis is given in Table 1. It was composed of amorphous alumina-silicate melt and a small amount 
of crystalline minerals, such as quartz, mullite, mica, etc. The contents of lime and sulfate were very low when compared to those of OPC and CKDs; also, the content of alkalis in FA was slightly higher than that of OPC and considerably lower than that of CKD Type 1.

Table 1 Chemical analysis of OPC, CKDs and FA.

\begin{tabular}{|c|c|c|c|c|c|}
\hline \multirow{2}{*}{ Oxide } & \multirow{2}{*}{$\begin{array}{l}\text { OPC } \\
\end{array}$} & \multicolumn{3}{|c|}{ CKD (\%) } & FA \\
\cline { 3 - 6 } & Type I & Type II & Type III & $(\%)$ \\
\hline $\mathrm{SiO}_{2}$ & 21.93 & 15.37 & 12.52 & 9.33 & 50.23 \\
\hline $\mathrm{Al}_{2} \mathrm{O}_{3}$ & 4.83 & 3.25 & 2.57 & 1.98 & 23.71 \\
\hline $\mathrm{Fe}_{2} \mathrm{O}_{3}$ & 3.35 & 2.33 & 2.38 & 2.67 & 13.58 \\
\hline $\mathrm{CaO}$ & 62.88 & 46.47 & 50.23 & 56.81 & 4.74 \\
\hline $\mathrm{MgO}$ & 1.12 & 1.58 & 1.85 & 2.60 & 0.99 \\
\hline $\mathrm{SO}_{3}$ & 2.45 & 3.05 & 4.29 & 5.38 & 1.30 \\
\hline $\mathrm{K}_{2} \mathrm{O}$ & 0.42 & 1.98 & 2.69 & 4.04 & 0.70 \\
\hline $\mathrm{Na}_{2} \mathrm{O}$ & 0.17 & 1.14 & 2.48 & 3.26 & 0.26 \\
\hline $\mathrm{Cl}^{-}$ & - & 2.50 & 3.72 & 5.64 & - \\
\hline $\mathrm{L.O.I}$ & 2.05 & 22.2 & 15.16 & 9.0 & 3.30 \\
\hline
\end{tabular}

Two types of blended cements were tested in this investigation, namely; CKD-OPC blend and CKDFA-OPC blend. In the CKD-OPC blend, each one of the three above CKDs was used as a partial replacement of $5,10,15,20,25,30,35,40,45$ and $50 \%$ of the cement content by weight. Based on the results of these blends, one of the three dusts (CKD of Type I) was used as an activator to FA in CKD. FA-OPC blends. In these blends, the total waste materials $(\mathrm{CKD}+\mathrm{FA})$ were substituted as a partial replacement of $5,10,15$ and $20 \%$ of the cement content by weight. At each replacement ratio of the waste materials, the proportions of CKD to the total waste materials $(\mathrm{CKD} /(\mathrm{CKD}+\mathrm{FA}))$ were $0,30,50$ and $70 \%$. The percentage weights of CKD and $\mathrm{FA}$ in the different CKD-FA-OPC blends as a partial replacement of the cement content is given in Table 2.

Table 2 Compositions of different CKD-FA-OPC blends.

\begin{tabular}{|l|l|c|c|c|c|}
\hline \multicolumn{2}{|c|}{$\begin{array}{c}\text { CKD-FA-OPC } \\
\text { blends }\end{array}$} & \multicolumn{4}{c|}{ CKD/(CKD+FA) } \\
\cline { 2 - 6 } & 0 & 30 & 50 & 70 \\
\hline Blend 1 & CKD (\%) & 0 & 1.5 & 2.5 & 3.5 \\
\cline { 2 - 6 } 5\% W.M & FA (\%) & 5 & 3.5 & 2.5 & 1.5 \\
\hline Blend 2 & CKD (\%) & 0 & 3.0 & 5.0 & 7.0 \\
\cline { 2 - 6 } $10 \%$ W.M & FA (\%) & 10 & 7.0 & 5.0 & 3.0 \\
\hline Blend 3 & CKD (\%) & 0 & 4.5 & 7.5 & 10.5 \\
\cline { 2 - 6 } $15 \%$ W.M & FA (\%) & 15 & 10.5 & 7.5 & 4.5 \\
\hline Blend 4 & CKD (\%) & 0 & 6.0 & 10.0 & 14.0 \\
\cline { 2 - 6 } 20\% W.M & FA (\%) & 20 & 14.0 & 10.0 & 6.0 \\
\hline
\end{tabular}

W. M: Waste materials
To ensure complete homogeneity of the blended cement, the dry constituents of each blend was homogenized for one hour in a porcelain ball mill using four balls. The physical properties of blended cement pastes were determined in terms of the water required for normal consistency, the initial and final setting times and the soundness, and compared to those of ordinary Portland cement. The water required for normal consistency and the setting times were measured according to ASTM C-187 and C-191 $[12,13]$, respectively. The soundness was measured by Le Chatelier method according to BS EN 196-Part 3 [14].

The compressive strength of blended cement mortars were measured according to ASTM C-109 [15] using $50 \mathrm{~mm}$ cube specimens and compared with that of OPC mortar. Three mortar specimens of each blend were tested for compressive strengths at ages of 7 and 28 days. The mortar was prepared by mixing one part of cement to 2.75 parts of sand by weight with water that was sufficient to obtain a flow diameter of $140 \pm 5 \mathrm{~mm}$ with 25 drops of the flow table test [16].

\section{RESULTS AND DISCUSSIONS}

\subsection{Properties of CKD-OPC Blended Cement}

The W/C ratio required to attain the standard consistency of cement pastes containing OPC blended with different types and amounts of CKD is shown in Fig. 1. As can be seen, the addition of CKD required more water content to produce a neat blend of normal consistency. Whichever the type of CKD used, the water content was increased with the increase in CKD content. The different types of CKD showed a noticeable variation in their water requirement; the water required for Type I CKD was considerably lower than that required for Type.II and Type III CKDs. This means that to produce blended cement paste with a W/C ratio still applicable to the maximum limit of standard water content, CKD of Type I can be used with a proportion higher than that of the other two types. For example, at a W/C ratio of 0.4 ; CKD of Type I could be used with a proportion more than $50 \%$, however, the upper limits of Type $I$ and Type III CKDs were 40 and $35 \%$, respectively.

The increase in water demand of blended cement paste may be attributed to the high amounts of alkalis, sulfates and volatile salts as well as the presence of a free lime in CKD. The free percentage of $\mathrm{CaO}$ requires a quantity of water to transform into $\mathrm{Ca}(\mathrm{OH})_{2}$. With the increase in $\mathrm{CKD}$ content the free $\mathrm{CaO}$ is also increased and so higher water content is required. Therefore, the use of CKD of Type I showed a lower water requirement due to its lower contents of alkalis, sulfates, volatile salts and $\mathrm{CaO}$ compared to those of Type II and Type III CKDs, see Table 1. 


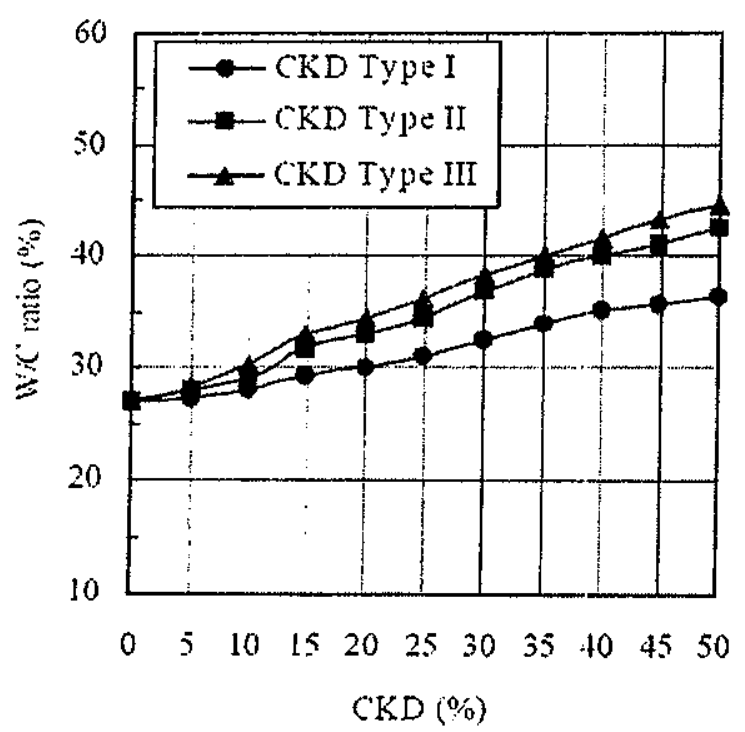

Fig. $1 \mathrm{~W} / \mathrm{C}$ ratio required for normal consistency of CKD-OPC blends vs. CKD\%.

The effect of CKD type and substitution on the initial and final setting times of blended cement paste are shown in Figs. 2 and 3. It was found that the addition of CKD elongated both the initial and final setting times of the cement pastes. The increase in CKD substitution was accompanied by an increase of setting times. However, the values of setting times of all blended cement pastes and at all CKD replacements were within the requirements of standard specifications for blended hydraulic cements; i.e. the initial setting time was $\geq 45$ minute and the final setting time was $\leq 7$ hours [17].

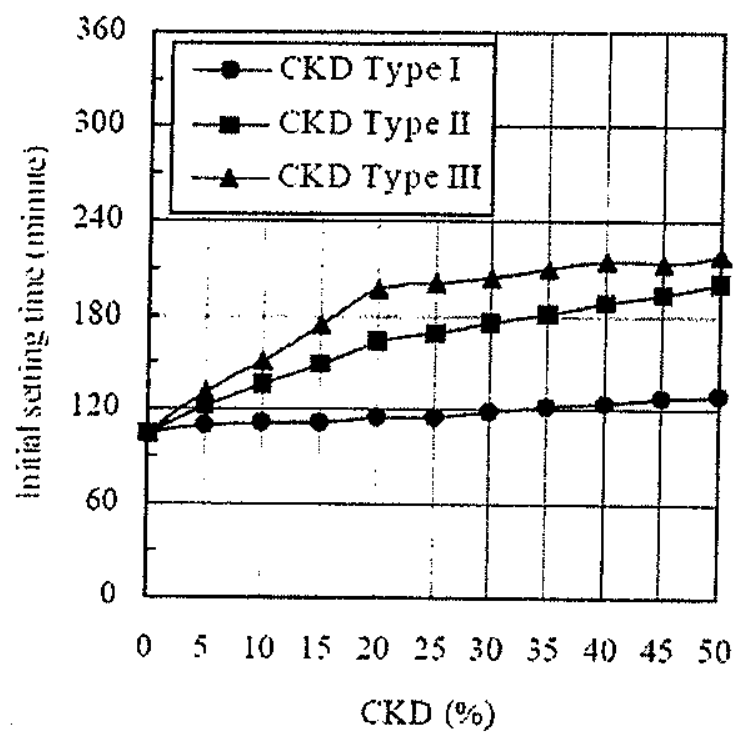

Fig. 2 Initial setting time of CKD-OPC blends vs. CKD\%.

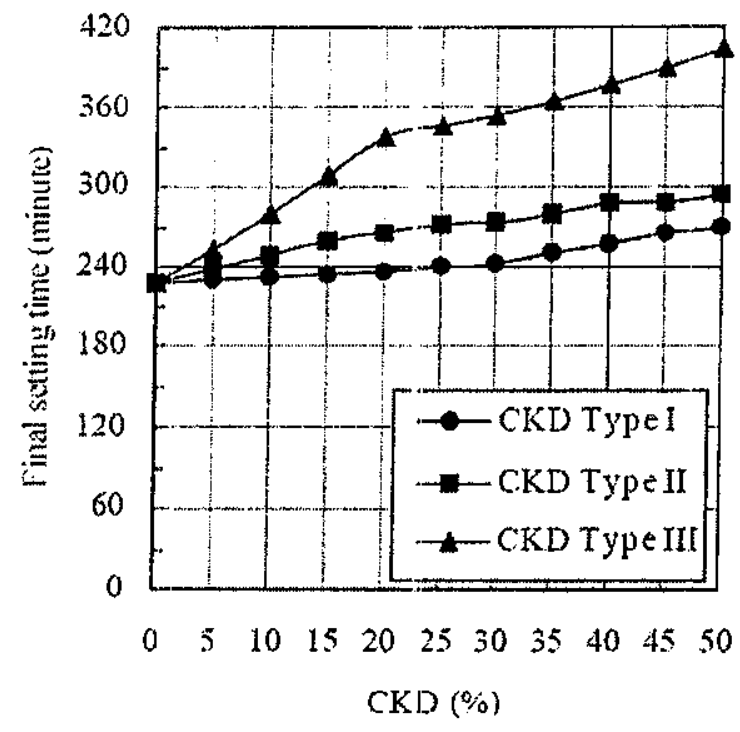

Fig. 3 Final setting time of $\mathrm{CKD}-\mathrm{OPC}$ blends vs. $\mathrm{CKL} \%$.

The effect of CKD on the setting times of blended cement paste varied from a roticeable effect in case of Type III, to a moderate elfect in case of Type II, and to a slight effect in case of Type I. This observation can be discussed by the chemical composition of CKDs (Table 1), where the contents of sulfate were $3.05,4.29$ and $5.38 \%$ in CKD of Types I, II and III, respective y. It is well known that $\mathrm{SO}_{3}$ elongates setting time. A.lso, the volatile alkalis $\left(\mathrm{Na}_{2} \mathrm{O}, \mathrm{K}_{2} \mathrm{O}\right)$ are both preferentially incorporated into $\mathrm{C}_{3} \mathrm{~A}$ to give orthorhombic form. $\mathrm{Na}_{2} \mathrm{O}$ orthorhombic $\mathrm{C}_{3} \mathrm{~A}$ is retarded in hydration [!8].

Figure 4 shows the effect of CKD incorporation on the soundness of blended cernent pastes. In general, the expansion of blended cennent paste was higher than that of OPC paste. As the CKD replacement increases, the expansion of blended cement paste will increase proportionally. This was true for the three types of CKDs used. However, in case of blended cement dust of Type I the increase in expansion with the increase in CKD substitution was very slight. The maximum expansion was reached at 50\% CKD with a value of about $5 \mathrm{~mm}$, which represents about $50 \%$ of the upper specified limit for expansion in hydraulic cement $(10 \mathrm{~mm})$. Higher values of expansion were observed for the other two blends. The maximum standard limit of expansion was taken place at a dust content of 35 and $20 \%$ for Type II and Type III CKD, respectively. Above these CKD contents, the expansion was abruptly increased.

The expansion of blended cement paste was increased with the increase ir! contents of $\mathrm{SO}_{3}$ and $\mathrm{K}_{2} \mathrm{O}$ of CKD used. The increase in $\mathrm{SO}_{3}$ leads to the formation of calcium sulpho-aluminate (ettringite) $3 \mathrm{CaO} . \mathrm{Al}_{2} \mathrm{O}_{3} \cdot 3 \mathrm{CaSO}_{4} \cdot 32 \mathrm{H}_{2} \mathrm{O}$, which gives about $100 \%$ increase of expansion. On the other side, as the 
amount of $\mathrm{SO}_{3}$ content decreases the ettringite decreases and then the expansion diminishes. Also, the increase of $\mathrm{K}_{2} \mathrm{O}$ tends to form gelatinous potassium silicate hydrate, which swells and increases the expansion too. Therefore, blends containing CKD of Type III showed higher expansion due to their higher contents of $\mathrm{SO}_{3}$ and $\mathrm{K}_{2} \mathrm{O}$, while blends containing $\mathrm{CKD}$ of Type I showed lower expansion due to their lower contents of $\mathrm{SO}_{3}$ and $\mathrm{K}_{2} \mathrm{O}$ (refer to Table 1).

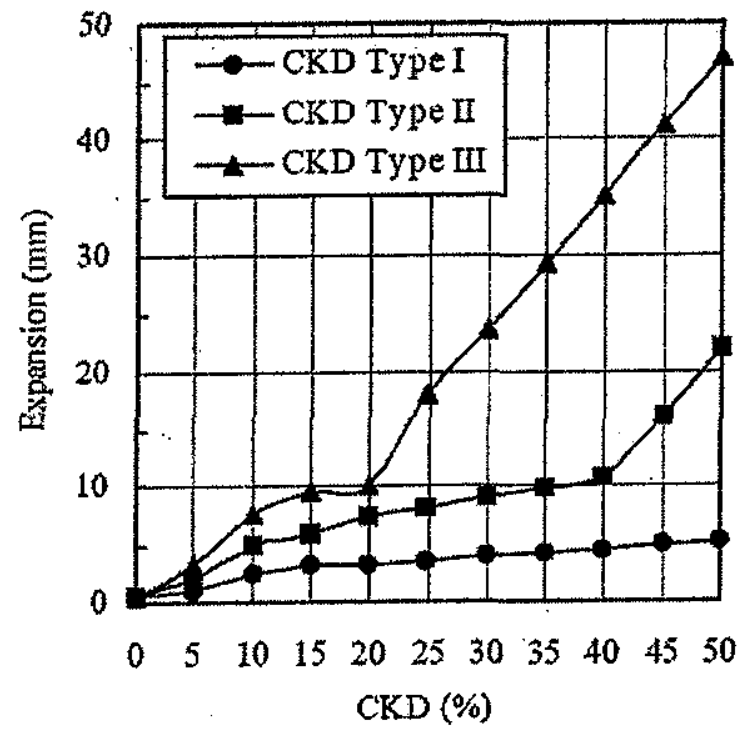

Fig, 4 Expansion of CKD-OPC blends vs. CKD\%.

Results of the ultimate compressive strength of mortar specimens prepared with different types of OPC-CKD blends at 7 and 28 days age are shown in Figs. 5, 6. The trends of compressive strength results were similar for all blends; the substitution of CKD as a partial replacement of $O P C$ was accompanied by a higher reduction in the compressive strength of blended cement mortars. This reduction was gradually increased with the increase in replacement ratio of $\mathrm{CKD}$.

The loss in compressive strength of blended cement mortars is attributed to the reduction in cement content and the increase in mixing water due to CKD incorporation. As mentioned above, the use of CKD requires more water content to attain the standard consistency of the cement paste. As the mixing water increases the compressive strength decreases due to the increase in the total porosity of mortar specimens. Also, the high chloride and sulfate contents of the CKD leads to the formation of chloro- and sulfoaluminate phases, which enhances the crystallization of hydration products leading to an opening of the pore system.

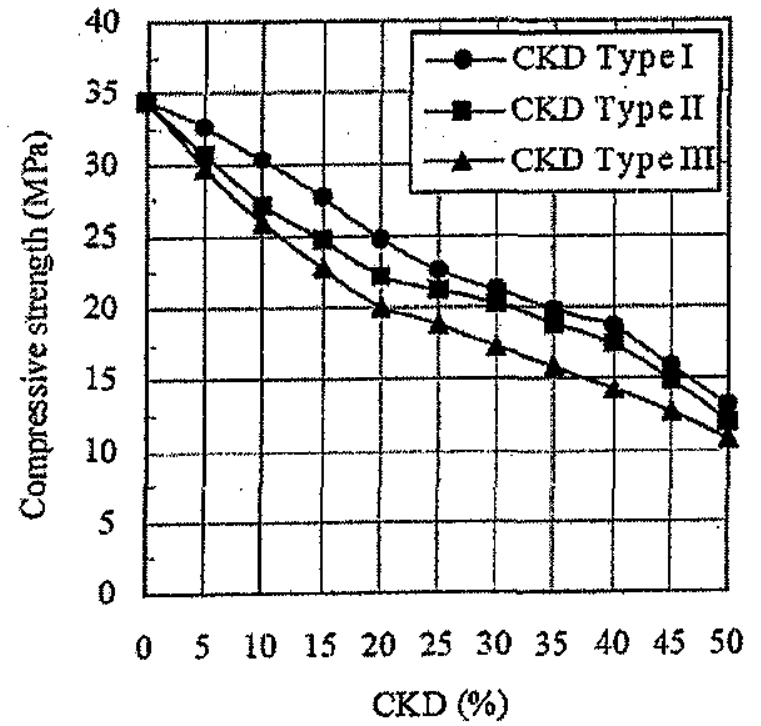

Fig. 5 7-day compressive strength of CKD-OPC blends vs. CKD\%.

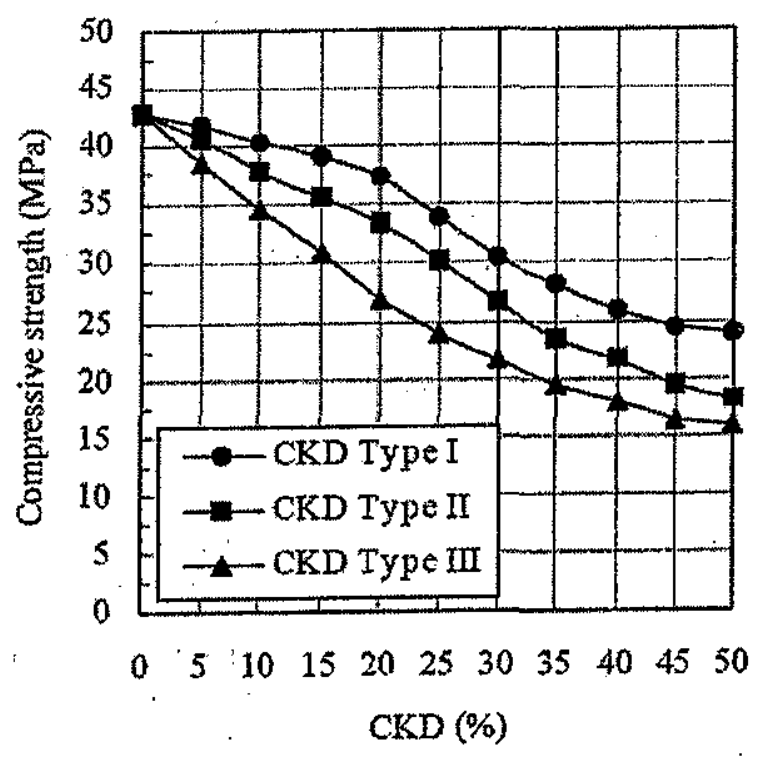

Fig. 6 28-day compressive strength of CKD-OPC blends vs. CKD\%.

The variation in the compressive strength between the three types of CKDs was mainly due to the chemical composition of the dust. As the chloride and sulfate contents of cement dust increases the compressive strength decreases, therefore, the reduction in compressive strength of blends with CKD of Type III was more pronounced than that of blends with CKD of Types I and II, see Figs. 5, 6. Also, the minimum recommended compressive strengths at 7 and 28 days age specified for blended hydraulic cements, which are 20 and $25 \mathrm{MPa}$ according to ASTM C-595 [17], were satisfied at a replacement ratio of 35,30 and $20 \%$ for CKD of Type I, II and III, respectively. 


\subsection{Properties of CKD-FA-OPC Blended Cement}

The $\mathrm{W} / \mathrm{C}$ ratio required for normal consistency of the blended cement pastes as a function of combined waste materials (CKD+FA) replacement is shown in Fig. 7. The results showed that increasing the ratio of waste materials in the blended cement paste significantly increased the amount of water required to produce a neat blend of normal consistency. From the above mentioned results, when the CKD of Type I with a quantity of $\leq 20 \%$ was used alone in the blended cement only a marginal increase in the water required for normal consistency was observed. This means that the increase in the water requirement of CKD-FA-OPC blends was mainly due to the presence of dry fly ash in the blend, which did not contribute to the hydration reactions. The increase in water requirement became less significant as CKD became the dominant waste material in the blend. For example, at $20 \%$ waste materials the $\mathrm{W} / \mathrm{C}$ ratio for blended cement paste with FA represented $100 \%$ of the waste materials was $54 \%$, and considerably decreased to $35 \%$ for blended cement paste with FA represented $30 \%$ of the waste materials.

Considering the effect of different combinations of the waste materials on the initial setting time of blended cement pastes, Fig. 8 reflects a higher increase in the initial setting time of the blends with the increase in waste materials replacement. A large jump in the initial setting time was observed in blends containing more than $10 \%$ waste materials, especially at high values of FA incorporation, where the values of initial setting time exceeded 5 hours as indicated by arrows in Fig. 8. Also, in blends with $\leq$ $10 \%$ waste materials the increase in setting time was significantly high when FA was the dominant waste material; however, it gradually became insignificant as the percentage of CKD in the blended waste materials was increased. This may be attributed to the high alkalinity of CKD that accelerates the hydration of blended cement.

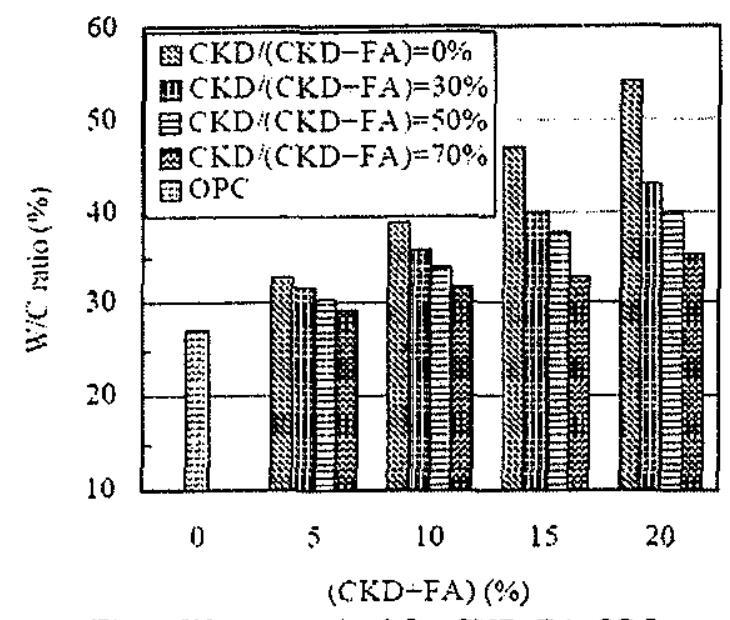

Fig. 7 Water required for CKD-FA-OPC blended cement.

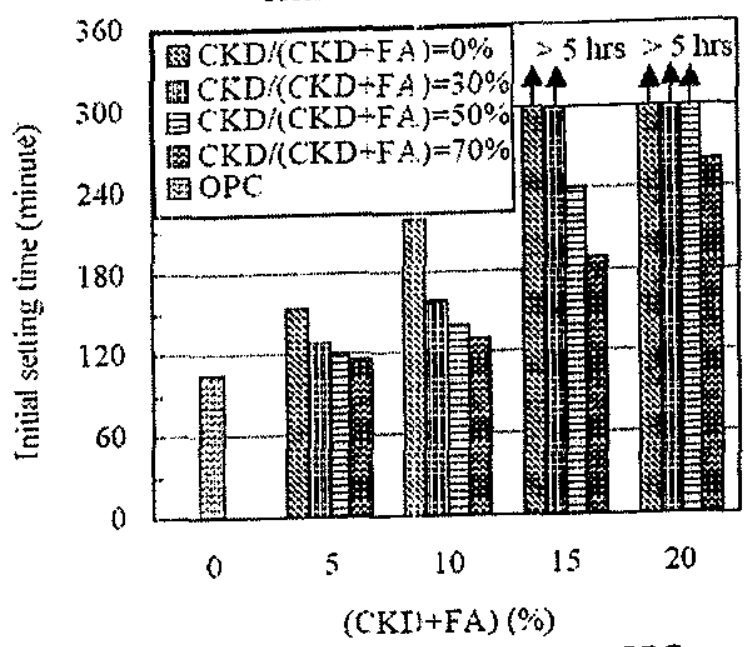

Fig. 8 Initial setting time of CKD-FA-OPC blended cement.

Figures 9, 10 present the 7- and 28-day compressive strength of the blended cernent mortars containing OPC with different amourts of waste materials. Generally, there was a less in the compressive strength of the mortar specimens with the inclusion of waste materials. This loss was more pronounced in case of specimens contained fly ash as the dominant waste material, and gradually decreased with the increase of $\mathrm{CKD} \%$ in the blended waste materials. At all the replacement ratios of waste materials, the less reduction in compressive sirength was occurred in mortar specimens containing $70 \% \mathrm{CKD}$ in the blended waste materials. This reduction was about 2 , $5.5,10$ and $14 \%$ for specimens containing $5,10,15$ and $20 \%$ waste materials and tested at 7 days age, respectively. The corresponding values for specimens tested at 28 days age were $3,5,16$ and $26 \%$, respectively. However, all values of the compressive strength of blended cement mortars at the different combinations of $\mathrm{CKD}$ and FA were more than the minimum recommended compressive strengths specified for blended hydraulic cements at 7 and 28 days age [17].

The higher reduction in compressive strength loss of mortar specimens incorporating $\geq 50 \%$ CKD in the blended waste materials may be attributed to the content and crystalline form of alkalis present in CKD, which makes it an excellent activator for the fly ash. The hydration rate of fly ash increases with the increase of alkalis in the blend [19]. The fly ash develops its pozzolanic activity and acts as hydraulic cements once their glass network disintegrates when attacked by $\mathrm{OH}^{-}$ions [8]. 

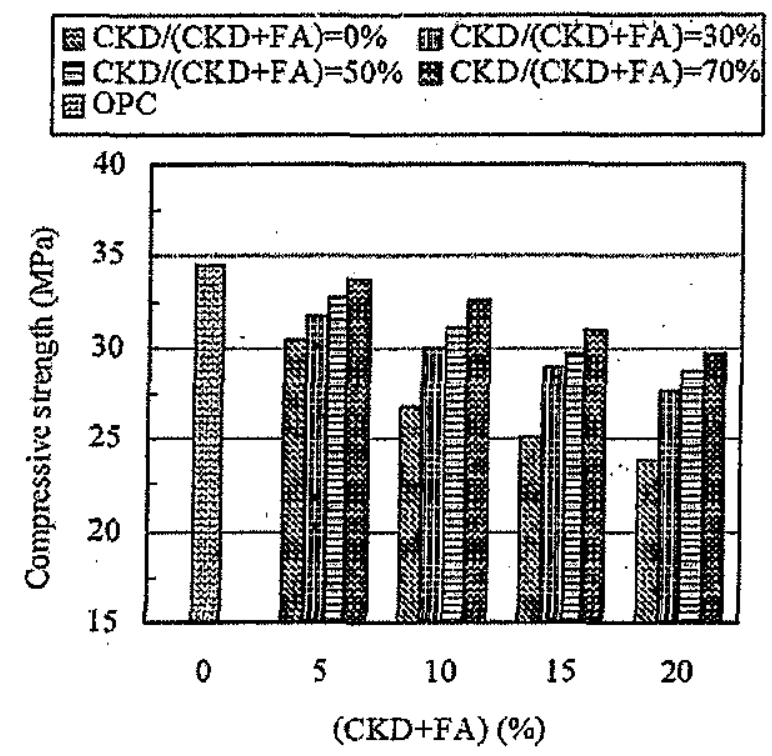

Fig. 9 7-day compressive strength of CKD-FAOPC blended cement.

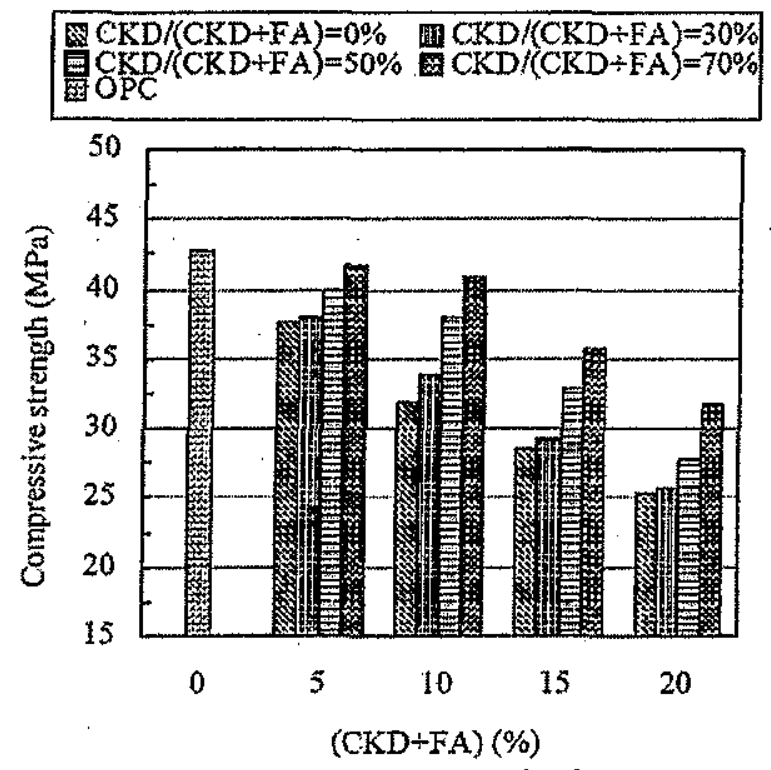

Fig. 1028 day compressive strength of CKD-FAOPC blended cement.

\section{CONCLUSIONS}

The experimental results in this study leads to the following conclusions:

1. The physical properties and compressive strength of CKD-OPC blended cement were highly influenced by the chemical composition of CKD. There was considerable increase in the $\mathrm{W} / \mathrm{C}$ ratio required for normal consistency and setting times; and noticeable decrease in the soundness and compressive strength of the blended cement with the increase of harmful oxides of the CKD used; $\mathrm{SO}_{3}, \mathrm{~K}_{2} \mathrm{O}, \mathrm{Na}_{2} \mathrm{O}, \mathrm{Cl}^{-}$and free $\mathrm{CaO}$.
2. The CKD of Type I, with the lower contents of harmful oxides, could be used in the production of blended cement with quantities up to $35 \%$ of the cement content without any effect on the physical properties of blended cement paste. However, the compressive strengths of blended cement mortar at 7 and 28 days age were significantly lower than the corresponding strengths of OPC mortar, but they were still within the minimum recommended strengths specified for blended hydraulic cements.

3. Other Types of CKDs, Type II and Type III, could also be used in the production of blended cement, but with the restriction that their contents in the blend did not exceed 30 and $20 \%$, respectively.

4. Properties of CKD-FA-OPC blended cement were very sensitive to the ratio of $C K D$ in the combined waste materials $(\mathrm{CKD}+\mathrm{FA})$. When the two materials were properly proportioned, the alkalis from CKD activated the hydration of FA and leading to a blend with satisfactory performance.

5. CKD-FA-OPC blends with $90 \%$ OPC and not more than 5\% FA had physical properties and strength comparable to those of OPC.

6. CKD-FA-OPC blend with $20 \%$ OPC and $6 \% \mathrm{FA}$ exhibited an acceptable increase in W/C ratio required for normal consistency, very high increase in the initial setting time ( $>4$ hours) and significant decrease in the 7 and 28 days compressive strengths compared to those of OPC. However, its compressive strength at 7 and 28 days age was considerably more than that of the minimum recommended strengths as specified for blended hydraulic cements.

\section{REFERENCES}

[1] Emery, J.J., Mackay, M.H., Umar, P.A., Vanderveer, D.G. and Pichette, R.J. (1992), "Use of Waste and By-products as Pavement Construction Materials", $45^{\text {th }}$ Canadian Geotechnical Conference, Toronto, Canada.

[2] Taha, R., Al-Rawas, A., Al-Harthy, A.S. and Qatan, A. (2002), "Use of Cement Bypass Dust as Filler in Asphalt Concrete Mixtures", Journal of Materials in Civil Engineering, July/August, pp. 338-343.

[3] ASTM (1991), "Standard Guide for Commercial Use of Lime Kiln Dusts and Portland CKDs", 1990 Annual Book of American Society for Testing and Materials Standards, Vol. 11.04, USA.

[4] Omar, A.F.M. (2008), "Utilization of Cement Kiln Dust in Concrete", M.Sc. Thesis, Faculty of Engineering, Altahadi University, Sirt, Libya, February. 
[5] Ahmed S.A. and Omar A.F.M. (2008), "Utilization of Cement Kiln Dust in Mortar and Concrete Mixes and in Production of Concrete Blocks", Submitted to Port-Said Engineering Research Journal.

[6] Miller, G.A. and Azad, S. (2000), "Influence of Soil Type on Stabilization with Cement Kiln Dust", Construction and Building Materials Journal, Vol. 14, pp. 89-97.

[7] Shoaib, M.M., Balaha, M.M. and AbdelRahman, A.G. (2000), "Influence of Cement Kiln Dust Substitution on the Mechanical Properties of Concrete", Cement and Concrete Research, Vol. 30, pp. 371-377.

[8] Abdel-Aleem, S., Abd-El-Aziz, M.A., Heikal, $M$. and El Daidamony, H. (2005), "Effect of Cement Kiln Dust Substitution on Chemical and Physical Properties and Compressive Strength of Portland and Slag cements", The Arabian Journal for Science and Engineering, Vol. 30, No. 2B, pp. 263-273.

[9] Daous, M.A. (2004), "Effect of Cement Kiln Dust and Fly Ash in Cement Blends in Saudi Arabia", Journal of King Abdulaziz University, Vol. 15 , No. 1, pp. 33-45.

[10]Konsta-Gdoutos, M.S., Shah, S.P. and Battacharja, S. (2002), "Development and Performance of Cement Kiln Dust-Slag Cement", International Conference on Challenges of Concrete Construction, University of Dundee, Dundee, UK, September.

[11] Shah, S.P. and Wang, K. (2005), "Development of Green Cement for Sustainable Concrete Using Cement Kiln Dust and Fly Ash", International
Workshop on Sustainable Development and Concrete Technology, pp. 15-23.

[12] ASTM C-187 (1998), "Standard Test Method for Normal Consistency of Hydraulic Cement", American Society for "resting and Materials Standards, USA.

[13] ASTM C-191 (2004), "Standard Test Method for Time of Setting of Hydraulic Cement by Vicat Needle", American Society for Testing and Materials Standards, USA.

[14]BS EN 196-3 (2005), "Methods of Testing Cement - Part3: Determination of Setting Times and Soundness", British Standard, UK.

[15] ASTM C-109 (2002), "Standard Test Method for Compressive Strength of Hydraulic Cement Mortars", American Society for Testing and Materials Standards, USA.

[16]ASTM C-230 (2003), "Standard Specification for Flow Table for Use in Tests of Hydraulic Cement", American Society for Testing and Materials Standards, USA..

[17]ASTM C-595 (2003), "Standard Specification for Blended Hydraulic Cements", American Society for Testing and Materials Standards, USA.

[18]Abo-El-Enein, S.A. (1997), "Utilization of Cement Kiln Dust in Cement Industry and Building Products", $1^{\text {st }}$ International Symposium on the Cement Industry, Assiut, Egypt, 8-10 November.

[19] Song, S. and Jennings, H.M. (1999), "Pore Solution Chemistry of Alkali-Activated Ground Granulated Blast-Furnace Slag", Cement and Concrete Research, Vol. 29, No. 2, pp. 159-170. 